\title{
An exciting time ahead
}

After a successful launch of the new Black Is White To Go chewing gum with active carbon earlier this year, this year's BDIA Dental Showcase is set to be the most exciting yet for Curaprox.

The chewing gum is the latest addition to the Black Is White family of products, designed to whiten teeth, prevent tooth decay and balance mouth flora for a fresh and beautiful smile.

Delegates can also expect to see a number of old favourites, including the extensive range of CS toothbrushes and CPS interdental brushes, as well as a number of Curaprox
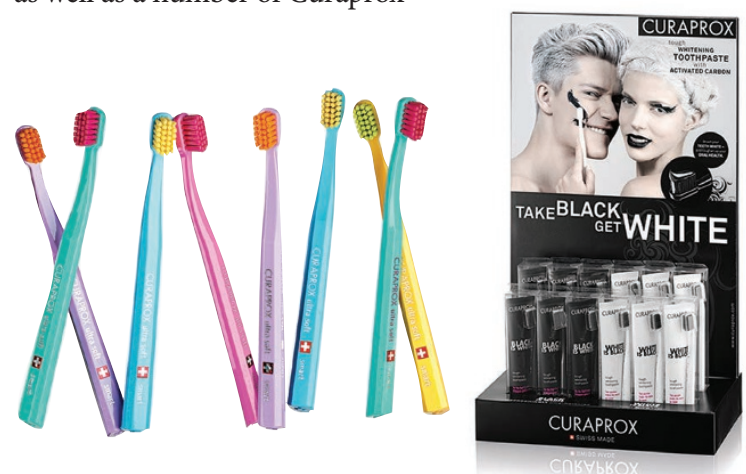

\section{Black, white and silver are the colours this season}

BDIA Dental Showcase marks the announcement of three important milestones for Philips Oral Healthcare and the company is inviting dental professionals to visit stand M40 to find out why black, white and silver are the colours this season.

In addition to a plethora of on-stand activity the company is fielding two expert speakers to lecture during the event in the Dental Update Theatre. Dr Ben Atkins will be presenting The Evolution of Oral Healthcare on 20 October 2017 between 15:30-16:15. Ben is a Trustee of the Oral Health Foundation and runs the out-ofhours dental service for Cheshire, provides treatment for the homeless in Manchester and is also an advisor to the BDA. He is an advocate for harnessing dental technology to encourage patient compliance.

Meanwhile dental hygienist and therapist Megan Fairhall - who has developed her own brand, \#Live to Smile - will be explaining how to harness social media in her lecture entitled Let's Be Social on 21 October 2017 at 15:30-16:15. Megan uses social media and networking
Baby products, which have proven to be a massive hit. The range of CURASEPT ADS (Anti-Discoloration System) mouth rinses will also be on display, offering all the benefits of chlorhexidine with minimal side effects.

As always, there will be an opportunity for delegates to try the Black Is White toothpaste, so if you haven't yet witnessed the amazing results, be sure to stop by stand G50 and see for yourself.

For more information call 01480862084 , email info@curaprox.co.uk or visit www. curaprox.co.uk.

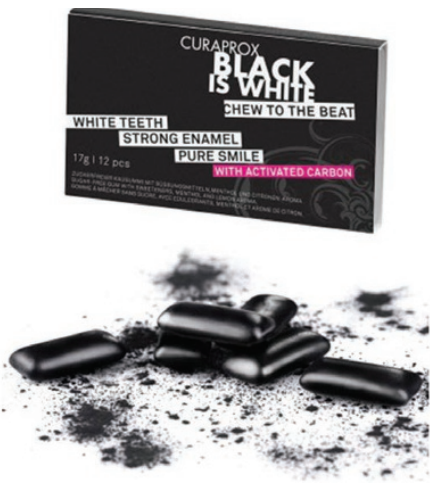

to increase patient leads and revenue, and will be letting delegates into her secrets to success.

Stand M40 will feature live Philips Zoom! Chairside whitening demonstrations, conducted by some of Philips' expert Key Opinion Leaders who will also be shedding light on a new Zoom! Chairside clinical study. CPD certification will be available to all delegates attending Philips' Zoom! lectures and demonstrations.

Also on the stand will be a series of brushing booths to allow delegates to trial the new digital innovation, the Philips Sonicare DiamondClean Smart first-hand. Everyone who trials the new premium app-connected brush at the show will then be able to buy the product and take advantage of an outstanding show offer, providing a substantial discount off the retail price. Philips' two other connected toothbrushes, FlexCare Platinum Connected and Sonicare For Kids will also take centre stage.

Visit stand M40 at BDIA Dental Showcase. www.philips.co.uk/dentalprofessional.
Headlining this year's event

Oral-B is once again the Headline Sponsor at this year's Dental Showcase. Much interest is expected in the company's flagship power toothbrush, Oral-B Genius. By combining motion sensor technology located in the brush, and video recognition using a smartphone's camera, all areas of the user's mouth can be tracked so that they know exactly where they've brushed and where they've missed! Patients receive instant feedback on the brushing of each zone of the mouth via the Oral-B App 4.1, including guidance on pressure applied and brushing duration.

The mechanical benefits of Oral-B's power toothbrushes complement the chemical efficacy afforded by their toothpaste. The new Oral-B Gum \& Enamel Repair Toothpaste will help patients address the increasing prevalence of gum or enamel issues. Featuring unique ActivRepair technology (with two sources of stannous: stannous fluoride and stannous chloride), it is the best clinically-proven toothpaste from Oral-B to help restore gum health and prevent enamel erosion.

Oral B will be on stands L2 and K10 at this year's BDIA Dental Showcase.

\section{Dental consultancy to offer advice}

A consultancy that specialises in recruitment, finance and the sale of dental practices will return to exhibit at BDIA Dental Showcase in October.

Dental Elite's advisors will be available to provide advice for industry professionals regarding practice sales and acquisitions, valuations, recruitment and finance.

Dental Elite's team has over 100 years' experience in the industry, with each person holding expertise in different fields. Members of the team will be at stand $\mathrm{K} 30$, with complimentary drinks provided for attendees from their wine bar.

The BDIA Dental Showcase is the largest dental show in the UK and attracts over 12,000 members of the dental profession and industry every year.

Dental Elite (www.dentalelite.co.uk) will be exhibiting on stand $\mathrm{K} 30$ on each of the three days. Pre-event enquiries can be made to info@dentalelite.co.uk or 01788545900. 